\title{
Analysis and selection criteria of photovoltaic panels for DHW
}

\author{
Artur Nemśs ,* $^{*}$ and Magdalena Nemś ${ }^{1}$ \\ ${ }^{1}$ Wroclaw University of Science and Technology, Faculty of Mechanical and Power Engineering, 50-370 Wroclaw, Poland
}

\begin{abstract}
The article discusses the issue of selecting power of photovoltaic panels for heating domestic hot water (DHW). It is indicated that the price of installation is several times lower than a couple of years ago. The authors present a method of selecting system power depending on DHW installation's heating requirements and the building's energy consumption. This algorithm allows for central heating requirements that are crucial in case of heating a building with solid fuel appliances. The described selection method uses heating power details obtained while drawing up Energy Performance Certificates, or the so-called heating degree-days, which enable to precisely determine the heating requirements in individual days of the year and select appropriate power of PV installation for the building's energy performance. In addition, the authors have calculated the heating losses occurring in different elements of installation and showed their influence on the system's power selection. The last part discusses the possibility of integrating PV installation used for heating DHW with the building's central heating system, in order to use the energy surplus.
\end{abstract}

\section{Nomenclature}

A - area of a photovoltaic panel, $\mathrm{m}^{2}$

$c_{w} \quad-$ specific heat of water, $c_{w}=4.19 \mathrm{~kJ} / \mathrm{kg} \cdot \mathrm{K}$

$D_{\text {ext }}$ - external diameter of the tank, $\mathrm{m}$

$d_{\text {int }} \quad$ - internal diameter of the tank, $\mathrm{m}$

$E_{p} \quad$ - amount of primary energy, $\mathrm{kWh} / \mathrm{m}^{2} \cdot$ year

Gr - Grashof number

I - current, A

$I_{S_{-} 45^{\circ}}$ - solar radiation at the angle of $45^{\circ}$ from the southern direction, $\mathrm{W} / \mathrm{m}^{2}$

$k_{t} \quad-$ corrective multiplier for hot domestic water temperature, -

$L$ - electrical cable length, m

$L_{i} \quad$ - number of reference units

$n-$ number of photovoltaic panels

$\mathrm{Nu} \quad$ - Nusselt number

$\mathrm{Pr} \quad$ - Prandtl number

$Q_{c a b}$ - heat lost in electrical cables, MJ

$\overline{Q_{c h}}$ - average annual heat demand for central heating, $\mathrm{MJ} /$ day

$Q_{c h_{i}} \quad$ - average daily heat demand for central heating, $\mathrm{MJ} / \mathrm{day}$

$Q_{d h w}$ - heat demand, $\mathrm{MJ} /$ day

$Q_{\text {loss }}$ - heat losses of the tank's surface, $\mathrm{MJ} /$ day

$Q_{P V}$ - amount of heat obtained from photovoltaic panels, $\mathrm{MJ} /$ day

$\dot{Q}_{b o t}$ - heat losses of the tank's bottom surface, W

$\dot{Q}_{c y l} \quad$ - heat losses of the tank's side surface, W

$\dot{q}_{l} \quad$ - stream of electrical cable heat loss, W/m

$\dot{Q}_{\text {loss }}$ - heat losses of the tank's surface, W

$\dot{Q}_{\text {top }} \quad$ - heat losses of the tank's top surface, W

$R_{e l} \quad$ - cable resistance, $\Omega$ $s \quad-$ cable cross-section, $\mathrm{mm}^{2}$

$T^{\prime} \quad$ - temperature of the tank's internal wall, $\mathrm{K}$

$T^{\prime \prime} \quad$ - temperature of the tank's external wall, $\mathrm{K}$

$T_{1} \quad$ - temperature of water in the tank, $\mathrm{K}$

$T_{2}$ - temperature outside the tank (ambient), $\mathrm{K}$

$t_{c w}$ - temperature of hot water in the faucet, ${ }^{0} \mathrm{C}$

$t_{d} \quad$ - daily average ambient temperature, ${ }^{0} \mathrm{C}$

$t_{\text {ow }}$ - temperature of cold water, ${ }^{0} \mathrm{C}$

$t_{r} \quad$ - annual average ambient temperature, ${ }^{0} \mathrm{C}$

$t_{w} \quad$ - average temperature inside a building, ${ }^{0} \mathrm{C}$

$V_{d h w}$ - unit usage of domestic hot water, $\mathrm{dm}^{3} /$ day

$V_{w} \quad$ - unit usage of water, $\mathrm{dm}^{3} /$ day

$\alpha_{1}-$ heat transfer coefficient on the inside of the tank, $\mathrm{W} / \mathrm{m}^{2} \cdot \mathrm{K}$

$\alpha_{2} \quad-$ heat transfer coefficient on the outside of the tank, W/ $\mathrm{m}^{2} \cdot \mathrm{K}$

$\delta_{\text {ins }}-$ thickness of the tank's insulation, $\mathrm{m}$

$\eta_{o}-$ proportion of hot water in total water demand per person

$\eta_{P V} \quad$ - efficiency of photovoltaic panels

$\lambda_{\text {ins }}-$ heat transfer coefficient of the tank's insulation, $\mathrm{W} / \mathrm{m} \cdot \mathrm{K}$

$v_{1} \quad$ - kinematic viscosity of water, $\mathrm{m}^{2} / \mathrm{s}$

$v_{2} \quad$ - kinematic viscosity of air, $\mathrm{m}^{2} / \mathrm{s}$

$\rho \quad-$ cable resistivity, $\Omega \cdot \mathrm{mm}^{2} / \mathrm{m}$

$\rho_{w} \quad-$ water density, $\mathrm{g} / \mathrm{m}^{3}$

$\tau \quad-$ time, $\mathrm{s}$

$\tau_{\text {us }} \quad$ - usage time, day

* Corresponding author: artur.nems@,pwr.edu.pl

(C) The Authors, published by EDP Sciences. This is an open access article distributed under the terms of the Creative Commons Attribution License 4.0 (http://creativecommons.org/licenses/by/4.0/). 


\section{Introduction}

There is a conviction in Poland that the best solar system allowing to prepare domestic hot water DHW are solar collectors. However, the constantly changing technology of photovoltaic panel production makes it necessary to consider, whether such a system could be a good alternative for collectors. As given in [1] the price of 3 photovoltaic cells of total power of $690 \mathrm{~W}$ in 2010 was PLN 9,000. Now, a 250W panel costs approximately PLN 500-800. What is more, it should be noted that their efficiency has increased, albeit slightly.

Both the installation of solar collectors and photovoltaic panels have advantages and disadvantages. However, one of the differences between them is that the set of photovoltaic panels heating water is less complicated. As shown in Figure 1, this system consists only of a set of panels, electrical cables, a control with temperature sensor and an electrical heater. Heater regulator, determining the maximum power point (MPP) can be included, yet, it is not indispensable.

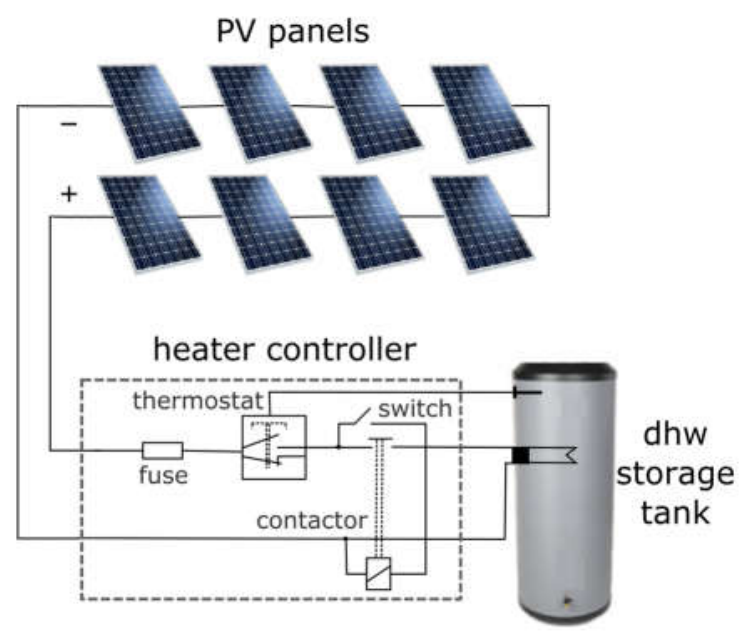

Figure 1. A simplified scheme of PV system used for heating DHW

\section{Domestic hot water demand}

It is of fundamental importance to determine the amount of energy required to prepare hot water when selecting the power of the heating installation. Currently, there are a few methods of determining the demand for DHW. One of them is described in [2] or in the Regulation on drawing up Energy Performance Certificates [3]. The formula determining the value is described with equation (1).

$$
\begin{gathered}
Q_{d h w}=V_{d h w} \cdot L_{i} \cdot c_{w} \cdot \rho_{w} \cdot\left(t_{c w}-t_{o w}\right) \cdot k_{t} . \\
\cdot \frac{\tau_{u s}}{1000 \cdot 3600}, M J / d a y
\end{gathered}
$$

According to the regulation, it is assumed that the demand for hot water per one inhabitant of a detached house is $35 \mathrm{dm}^{3} /$ day.

A slightly different methodology of calculating the demand is presented in EN 15316-3 standard [4] described by relationship (2).

$$
Q_{d h w}=\frac{V_{w} \cdot L_{i} \cdot c_{w} \cdot \rho_{w} \cdot\left(t_{c w}-t_{o w}\right) \cdot \eta_{o}}{10^{6}}, M J / d a y
$$

It does not take account of the usage time nor the coefficient resulting from the temperature of domestic hot water. However, it uses the information about total water demand. Such a solution allows for individual determination of needs, depending on the water used by a single person. In case of selecting installation for a building that is being built, it is not possible to determine the demand on the basis of water consumption data read from the counter, hence - average values can be adopted, being approximately $100 \mathrm{dm}^{3} /$ person day for single family houses. For such values, it is assumed that the proportion of hot water in total demand for water is $60 \div 70 \%$. Assuming that there are 4 people living in the house, each using $70 \mathrm{dm}^{3} /$ day, we get a daily demand on the level of $41.06 \mathrm{MJ}$. For simplification reasons it is assumed that water in the waterworks has a fixed annual temperature $10^{\circ} \mathrm{C}$, and it is heated up to $45^{\circ} \mathrm{C}$, so the demand is fixed throughout the whole year.

As it results from the above discussion, a minimal volume of accumulative tank should be $280 \mathrm{dm}^{3}$, so that is possible to accumulate the whole necessary energy and distribute it at any time during the day. Such a DHW tank is characterised with heat losses that need to be added to the required demand for water used to prepare DHW. When selecting the tank, one can use the product's manufacturer data sheet and read the value of heat losses. However, the authors' experience shows that these values differ from those calculated while determining heat transfer. Thus, the authors suggest determining the value of heat losses related to accumulation in the tank, which is not perfect, with the use of heat transfer equations resulting from Fourier's and Newton's laws. They assume, that the transfer of heat from the tank to the surroundings is done by way of convection in space that is unlimited inside and outside, as well as by heat conduction through insulation. Calculations are done for the determined one-dimension heat transfer, i.e.:

- temperature field does not change in time, it only depends on the location,

- temperature changes in one direction in space.

The following are not taken into account:

- heat transfer by way of radiation due to relatively small difference of temperatures,

- heat conduction through the tank's construction due to the fact that heat resistance of steel is more than 1,000 times smaller than that of polyurethane foam, which constitutes insulation.

Due to existing type series, it is assumed that the tank's volume is $300 \mathrm{dm}^{3}$, other assumptions are presented in Table 1.

Table 1. Data adopted for heat calculations

\begin{tabular}{|c|c|l|c|c|}
\hline$T_{1}, \mathrm{~K}$ & $T_{2}, \mathrm{~K}$ & Insulating material & $\delta, \mathrm{m}$ & $\lambda, \mathrm{W} / \mathrm{mK}$ \\
\hline 328 & 2933 & polyurethane foam & 0.1 & 0.023 \\
\hline
\end{tabular}

Water and air characteristics depending on temperature are shown in Table 2. 
Table 2. Values of water and air characteristics required for calculations of heat losses

\begin{tabular}{|l|c|}
\hline$P r_{1},-$ & 3.3 \\
\hline$P r_{2},-$ & 0.7 \\
\hline$v_{1}, \mathrm{~m}^{2} / \mathrm{s}$ & $0.52 \cdot 10^{-6}$ \\
\hline$v_{2}, \mathrm{~m}^{2} / \mathrm{s}$ & $15.06 \cdot 10^{-6}$ \\
\hline$\lambda_{1}, \mathrm{~W} / \mathrm{m} \cdot \mathrm{K}$ & 0.654 \\
\hline$\lambda_{2,}, \mathrm{~W} / \mathrm{m} \cdot \mathrm{K}$ & 0.026 \\
\hline$\beta, 1 / \mathrm{K}$ & $4.8 \cdot 10^{-4}$ \\
\hline
\end{tabular}

The tanks' covers are treated like two flat walls, whereas, if a horizontal surface transfers heat upwards, then the calculated value of heat transfer coefficient $\alpha$ has been increased by $30 \%$, and in case of a cover transferring heat downwards, decreased by $30 \%$; whereas side wall was calculated on the basis of equations dedicated for cylindrical surfaces.

In order to obtain the final value of heat losses, we should sum up heat streams related to flat surfaces and cylindrical surface, indirectly using equations and relationships convergent with heat conduction and convective heat transfer, being the process of simultaneous transfer and penetration [5]. On the basis of the following equations, a system with eleven unknowns was written and solved in an iterative way. Conduction and transfer of heat through a single-layer flat partition is shown in Figure 2 and heat streams are described with equations $(3 \div 5)$.

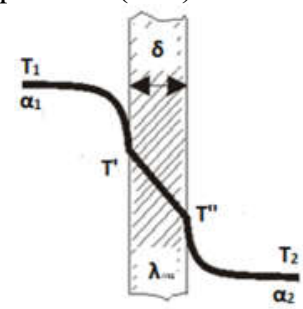

Figure 2. Conduction and transfer of heat through the tank's wall

$$
\begin{gathered}
\dot{Q}_{\text {top }}=\left(T_{1}-T^{\prime}\right) \cdot \alpha_{1} \cdot\left(\pi \cdot \frac{d_{\text {int }}{ }^{2}}{4}\right) \\
\dot{Q}_{\text {top }}=\frac{\left(T^{\prime}-T^{\prime}\right)}{\frac{\delta_{\text {ins }}}{\lambda_{\text {ins }}}} \cdot \pi \cdot \frac{\left(\frac{d_{\text {int }}+D_{\text {ext }}{ }^{2}}{2}\right)}{4} \\
\dot{Q}_{\text {top }}=\left(T^{\prime \prime}-T_{2}\right) \cdot \alpha_{2} \cdot\left(\pi \cdot \frac{D_{\text {ext }}{ }^{2}}{4}\right)
\end{gathered}
$$

Heat transfer coefficients $\alpha$ have been determined according to equations (6) and (7), whereas for convective heat transfer $\alpha$ depends on Nusselt number described with equations (9) and (10).

$$
\begin{gathered}
\alpha_{1 k p}=1.3 \cdot \frac{N u_{1} \cdot \lambda_{1}}{d_{\text {int }}} \\
\alpha_{2 k p}=1.3 \cdot \frac{N u_{2} \cdot \lambda_{2}}{D_{\text {ext }}} \\
N u_{1}=C \cdot\left(G r_{1} \cdot P r_{1}\right)^{n} \\
N u_{2}=C \cdot\left(G r_{2} \cdot P r_{2}\right)^{n}
\end{gathered}
$$

Constant $C$ and $n$ in equations (9) and (10) depend on the scope of Gr$\cdot$ Pr product in the following way [5]:

$$
\begin{array}{ccc}
\mathrm{f} \text { or }(G r \cdot P r) \leq 10^{-3} & \mathrm{C}=0.5 & \mathrm{n}=0 \\
10^{-3} \leq(G r \cdot P r) \leq 500 & \mathrm{C}=1.18 & \mathrm{n}=0.125 \\
500 \leq(G r \cdot P r) \leq 2 \cdot 10^{7} & \mathrm{C}=0.54 & \mathrm{n}=0.250 \\
2 \cdot 10^{7} \leq(G r \cdot P r) \leq 1 \cdot 10^{13} & \mathrm{C}=0.135 & \mathrm{n}=0.333
\end{array}
$$

In $\mathrm{Gr} \cdot \operatorname{Pr}$ product the first component - Prandtl number was read from the tables, whereas Grashof number was calculated on the basis of equation (11) and (12).

$$
\begin{gathered}
G r_{1}=\frac{g \cdot \beta_{1} \cdot\left(T_{1}-T^{\prime}\right) \cdot d_{i n t}{ }^{3}}{v_{1}{ }^{2}} \\
G r_{2}=\frac{g \cdot \frac{1}{\frac{T^{\prime \prime}+T_{2}}{2}} \cdot\left(T^{\prime \prime}-T_{2}\right) \cdot D_{e x t}{ }^{3}}{v_{2}{ }^{2}}
\end{gathered}
$$

An almost identical system as the one above was solved for the bottom cover, the difference being only in the multiplier of equations (6) and (7), with number 0.7

\begin{tabular}{|c|c|c|c|c|c|c|}
\hline \multicolumn{7}{|c|}{ Side wall - cylindrical } \\
\hline$T^{\prime}$ & $T^{\prime \prime}$ & $Q_{c y l}$ & $\alpha_{1}$ & $\alpha_{2}$ & $N u_{1}$ & $\mathrm{Nu}_{2}$ \\
\hline \multirow{2}{*}{$\mathrm{K}$} & \multirow{2}{*}{$\mathrm{K}$} & \multirow{2}{*}{ W } & W & W & \multirow{2}{*}{-} & \multirow{2}{*}{-} \\
\hline & & & $\overline{\mathrm{m}^{2} \cdot \mathrm{K}}$ & $\overline{\mathrm{m}^{2} \cdot \mathrm{K}}$ & & \\
\hline 327.9 & 295.6 & 17.5 & 139.4 & 2.3 & 226.5 & 109.9 \\
\hline \multicolumn{7}{|c|}{ Top cover } \\
\hline$T^{\prime}$ & $T^{\prime \prime}$ & $Q_{t o p}$ & $\alpha_{1}$ & $\alpha_{2}$ & $N u_{1}$ & $\mathrm{Nu}_{2}$ \\
\hline \multirow{2}{*}{$\mathrm{K}$} & \multirow{2}{*}{$\mathrm{K}$} & \multirow{2}{*}{ W } & W & W & \multirow[t]{2}{*}{4} & \multirow{2}{*}{ - } \\
\hline & & & $\overline{\mathrm{m}^{2} \cdot \mathrm{K}}$ & $\overline{\mathrm{m}^{2} \cdot \mathrm{K}}$ & & \\
\hline 327.9 & 294.8 & 2.5 & 174.4 & 3.1 & 112.8 & 69.5 \\
\hline \multicolumn{7}{|c|}{ Bottom cover } \\
\hline$T^{\prime}$ & $T^{\prime \prime}$ & $Q_{b o t}$ & $\alpha_{1}$ & $\alpha_{2}$ & $N u_{1}$ & $\mathrm{Nu}_{2}$ \\
\hline \multirow[b]{2}{*}{ K } & \multirow[b]{2}{*}{ K } & \multirow{2}{*}{ W } & W & W & \multirow{2}{*}{-} & \multirow[b]{2}{*}{-} \\
\hline & & & $\overline{m^{2} \cdot K}$ & $\overline{m^{2} \cdot K}$ & & \\
\hline 327.9 & 295.8 & 2.4 & 108.7 & 2.0 & 130.6 & 80.4 \\
\hline
\end{tabular}
instead of 1.3. Whereas for the side cylindrical wall, heat transfer is described with different equations $(13 \div 15)$.

$$
\begin{gathered}
\dot{Q}_{c y l}=\left(T_{1}-T^{\prime}\right) \cdot\left(\pi \cdot d_{i n t} \cdot \alpha_{1 k p}\right) \cdot\left(L-2 \delta_{i n s}\right)(13) \\
\dot{Q}_{c y l}=\left(T^{\prime}-T^{\prime \prime}\right) \cdot \frac{\pi \cdot 2 \cdot \lambda_{i z}}{\ln \left(\frac{D_{e x t}}{d_{i n t}}\right)} \cdot\left(L-\delta_{i n s}\right) \\
\dot{Q}_{c y l}=\left(T^{\prime \prime}-T_{2}\right) \cdot\left(\pi \cdot D_{\text {ext }} \cdot \alpha_{2 k p}\right) \cdot L
\end{gathered}
$$

The remaining equations are correlative with equations for the flat wall, however the difference is the characteristic dimension - diameter in case of the cover and height $L$ in case of the cylindrical wall. Aggregate results for the systems of equations are shown in Table 3.

Table 3. Table of results for losses in DHW tank

According to equation (16) after summing up the values of three heat streams for a 3001 hot domestic water tank, the obtained value is $\dot{Q}=22.5 \mathrm{~W}$.

$$
\dot{Q}_{l o s s}=\dot{Q}_{t o p}+\dot{Q}_{b o t}+\dot{Q}_{c y l}
$$

According to equation (17) it corresponds to $1.9 \mathrm{MJ}$ of energy lost during one day. 


$$
\begin{gathered}
Q_{\text {loss }}=\dot{Q}_{\text {loss }} \cdot \tau \cdot 3600 \cdot 10^{-6}=22.5 \cdot 24 \cdot 3600 \\
10^{-6}=1.9 \mathrm{MJ}
\end{gathered}
$$

After including the losses, the value of an aggregate amount of energy required for DHW tank during one day is obtained.

Energy lost during a day is less than $5 \%$ of energy required to heat domestic hot water. As shown in Figure 3 it increases as the tank's volume increases. For a 600 $\mathrm{dm}^{3}$ tank, appropriate for an 8-person family, the losses are $3.4 \%$, whereas in case of $900 \mathrm{dm}^{3}$ volume, they are only $3 \%$. In the given case it is possible to omit the complicated calculation process, yet, the tank's insulation is of great importance, because these losses may prove significant for a tank with less insulation.

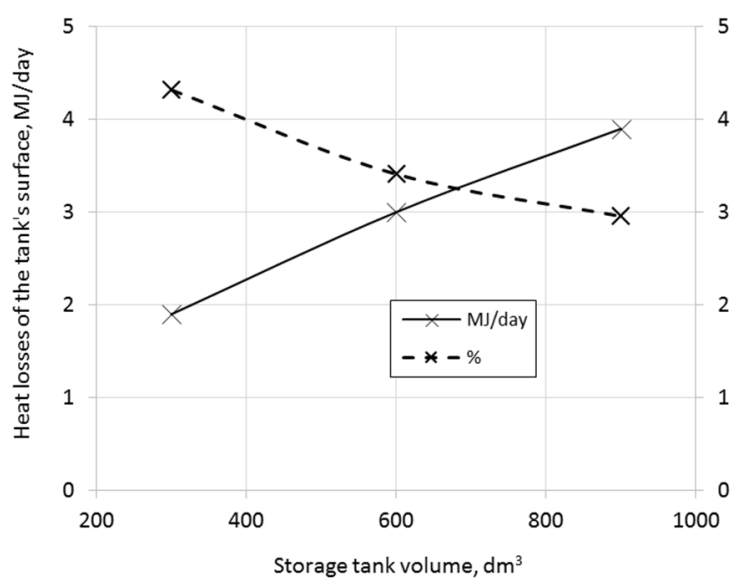

Figure 3. Daily heat losses from the tank

\section{Solar installation gains}

As the next step of the project, it is necessary to select data related to insolation in the given area. In Poland this information (selected from among at least 30 summer measurements) is shared on the Ministry of Infrastructure and Construction's website [6]. It informs about the amount of energy obtained in individual months of the year, as has been shown in Figure 4a. These data are rather demonstrative and do not provide information about insolation on individual days of the year. The Ministry's website also shows hourly data of radiation reaching the surface. They can be used to prepare a table of daily amount of energy in individual weeks (Figure 4b) or days (Figure 4c).

Average weekly data can be used for further project calculations and are especially valuable when one wants to make quick, but estimative calculations. Daily, not averaged data related to insolation allow to make proper calculations (only hourly data are more detailed than those, yet their amount can cause calculative problems). This data will be included in further calculations.

Assuming that the discussed system will consist of panels of $250 \mathrm{~W}$ power each, the amount of energy obtained can be calculated with equation (18), The remaining parameters of a model panel have been put together in Table 4.

$$
Q_{P V}=\eta_{P V} \cdot I_{S_{-} 45^{0}} \cdot A \cdot \mathrm{n} \cdot \frac{3600}{10^{6}}, M J / \text { day }
$$

Table 4. Parameters of a selected PV module

\begin{tabular}{|c|c|c|c|c|c|c|}
\hline$N_{P V}$ & $\eta$ & $U_{m p}$ & $I_{m p}$ & $U_{o c}$ & $I_{s c}$ & $a \cdot b \cdot c$ \\
\hline $\mathrm{W}$ & - & $\mathrm{V}$ & $\mathrm{A}$ & $\mathrm{V}$ & $\mathrm{A}$ & $\mathrm{mm}$ \\
\hline 250 & 0.153 & 30.4 & 8.23 & 37.6 & 8.81 & $1650 \cdot 992 \cdot 45$ \\
\hline
\end{tabular}

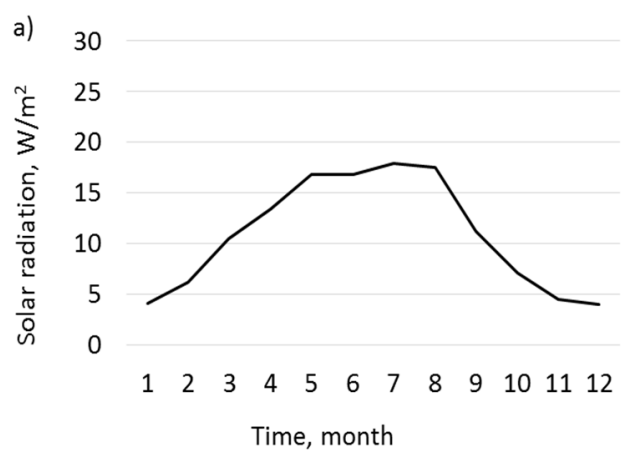

b)
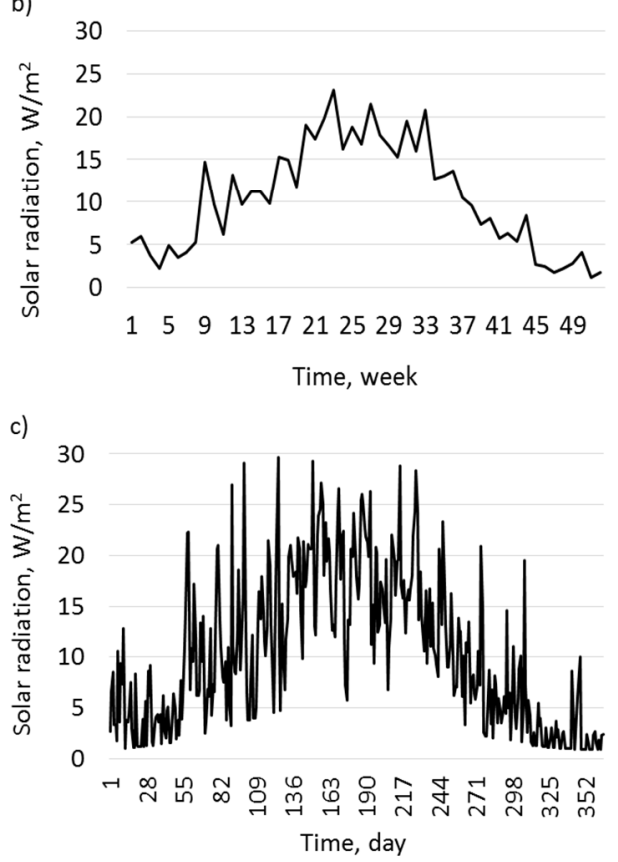

Figure 4. The amount of energy striking the surface at the angle of $45^{\circ}$ from the south in Warsaw during a day: a) average monthly, b) average weekly, c) daily, not average

The amount of energy obtained during one day from one panel is small, so panels should be joined in order to obtain the demanded power.

It is worth noticing that the first solution (Fig. 5) is beneficial in terms of savings, as the whole energy gained is used to cover DHW needs. However, such a system needs to cooperate with an additional source of energy in order to cover the remaining needs.

The other version (Figure 6) assumes that the needs of DHW will be totally covered per year. It turns out to be possible to achieve after using over 100 panels. It causes the occurrence of huge surpluses of energy during summer, which need to be used (sold or used for other purposes) so that this system can be profitable at all. 


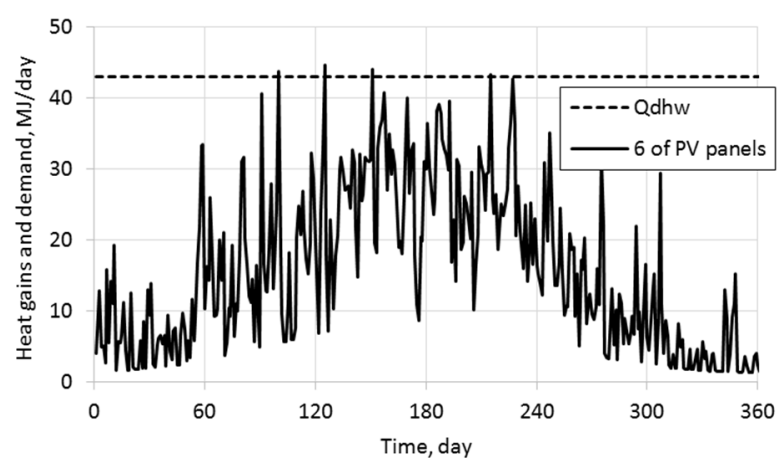

Figure 5. Annual summary of daily gains of energy obtained from panels for a minimum number of pieces (6) allowing to cover DHW requirements

If the PV are to cooperate with a heating device that is not automated (coal boiler, biomass boiler, fireplace, etc.) then their number should be selected in such a way that the additional device's work is necessary only in the heating season, when it has to fulfil the needs of central heating. In such a case, one needs to know the building's energy consumption to select a proper number of PVs. For this purpose, one should make heat calculations or use the data related to energy requirements, found, for instance, in energy performance certificates.

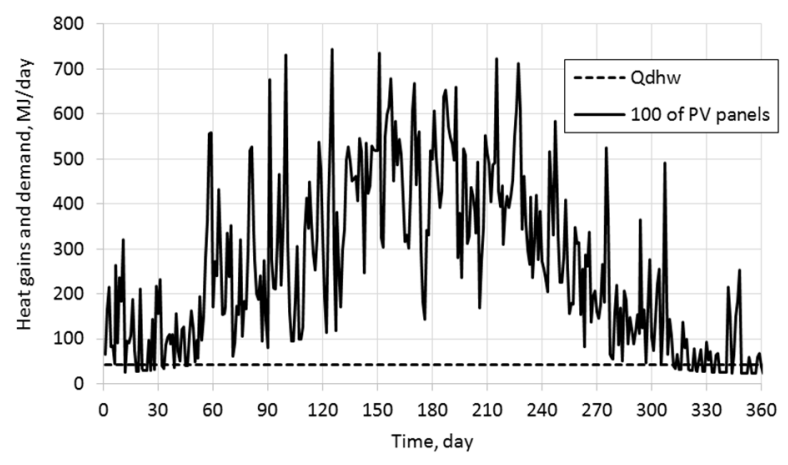

Figure 6. Annual summary of daily gains of energy obtained from panels for a maximum number of pieces (100) allowing to cover DHW requirements throughout the whole year

For the model calculations it is assumed that $E_{p}$ building's energy consumption is $100 \mathrm{kWh} / \mathrm{m}^{2}$.year, and its surface is $150 \mathrm{~m}^{2}$. It means that average daily requirements of energy necessary to provide comfort are $148 \mathrm{MJ} /$ day. However, heating demands are not constant throughout the year, so, in order to determine them in individual days of the year, the method of average daily air temperature has to be used. It assumes that heating is turned off when the average daily ambient air temperature is higher than the base temperature (temperature inside the building). This method allows to determine the number of heating degree-days [7]. In order for the calculations of thermal energy requirements to be more reliable, the parameter of limit temperature is additionally used. Its use decreases the number of degree-days by months outside the heating season as well as first (September) and last (June) days of the heating season [8].
First, average heat demand for the purpose of central heating has to be determined, knowing the building's energy consumption and heat necessary to prepare domestic hot water.

$$
\overline{Q_{c h}}=E_{p}-\left(Q_{d h w}+Q_{\text {loss }}\right), \mathrm{MJ} / \mathrm{day}
$$

Then, average daily heat demand for the purpose of central heating is calculated with the use of average daily temperatures (in the given example they are data for Warsaw, available at the Ministry of Infrastructure and Construction's website [6]).

$$
Q_{c h_{i}}=\left\{\begin{array}{c}
\frac{\overline{Q_{c h}} \cdot\left(t_{w}-t_{d}\right)}{t_{w}-t_{r}} \text { for }_{d}<t_{w} \\
0 \quad \text { for } t_{d}>t_{w}
\end{array}, \mathrm{MJ} /\right. \text { day }
$$

Calculated daily requirements for $Q_{c h}, Q_{d h w}$ and the building's energy consumption $E_{p}$ per year are shown in Figure 7 .

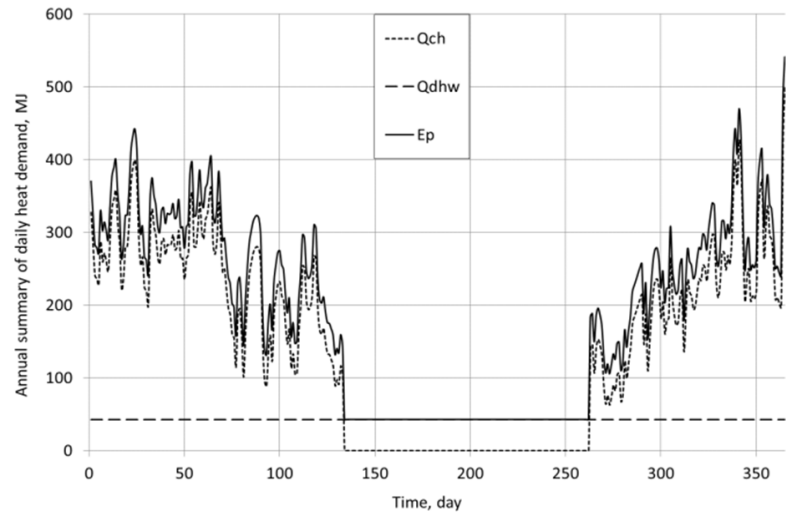

Figure 7. Daily heat demand per year

The data presented show the time when the heating season begins. That is why it is possible to select such a number of panels that allows to completely cover the DHW requirements during summer period, which is shown in Figure 8.

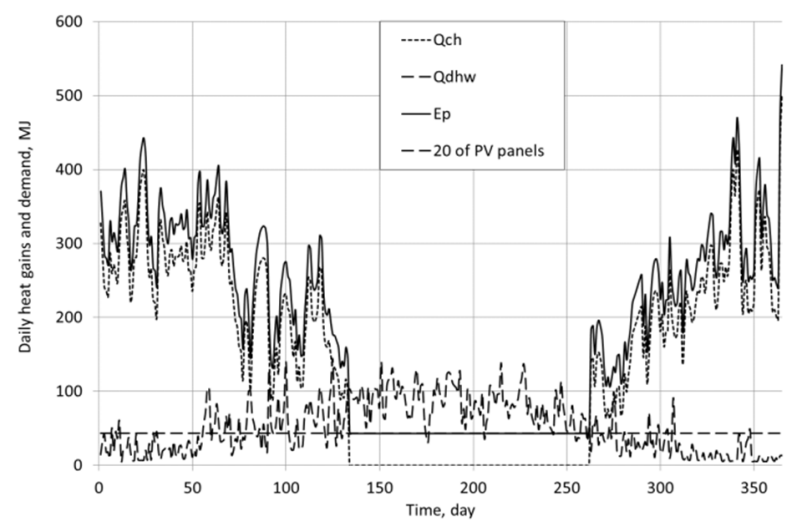

Figure 8. Annual summary of daily gains obtained from panels for the number of pieces (20) allowing to completely cover DHW requirements during summer period

It is worth noticing that PV efficiency depends on irradiance (Fig. 9) and on temperature to some extent. This should be kept in mind at the stage of calculations. 


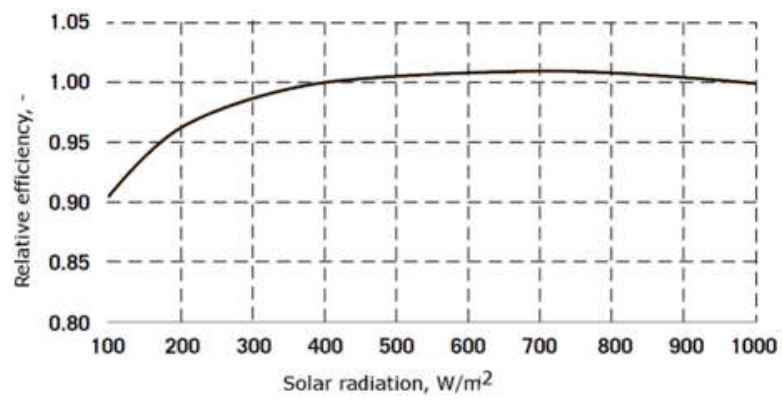

Figure 9. The typical change in module efficiency at an irradiance of $200 \mathrm{~W} / \mathrm{m}^{2}$ in relation to $1000 \mathrm{~W} / \mathrm{m}^{2}$ (at $20^{\circ} \mathrm{C}$ )

However, it turns out that it causes only slight changes in the amount of energy received, as a much bigger part of energy is obtained at an irradiance of over $400 \mathrm{~W} / \mathrm{m}^{2}$ than of approximately $200 \mathrm{~W} / \mathrm{m}^{2}$. That is why deviations from nominal efficiency can be excluded.

The last element used to establish the relation of necessary energy to obtained energy is the determination of losses on cables connecting panels with the electrical heater placed inside the DHW tank. The stream of lost energy due to heat emitted from the cable through which current flows is described by Joule heat (21):

$$
\dot{q}_{l}=I^{2} \cdot R_{e l},,
$$

where electrical resistance depends on cross section $s$ and resistivity $\rho$ and is calculated on the basis of equation (22).

$$
R_{e l}=\frac{\rho}{s}, \Omega
$$

Assuming that the cable's diameter is $6 \mathrm{~mm}$ and resistivity is $0.017 \Omega \cdot \mathrm{mm}^{2} / \mathrm{m}$ it is necessary to determine current $I$ flowing through the cables, in order to determine the total amount of heat emitted by cables (23) of assumed length of $20 \mathrm{~m}$.

$$
Q_{c a b}=\frac{\dot{q}_{l} \cdot L \cdot \tau}{10^{6}}, M J
$$

In order to determine the current flowing through the cables it is necessary to determine the configuration of panels. Knowing that maximum voltage is $30.4 \mathrm{~V}$, and current is $8.23 \mathrm{~A}$ one can notice that it is possible to make a serial connection of all panels, as the maximum voltage will be only slightly bigger than $600 \mathrm{~V}(750 \mathrm{~V}$ in open system), and these installations are designed to work with maximum voltage of $1 \mathrm{kV}$. Serial connection will ensure lowest current possible, which, according to equation (21) will cause the smallest losses. Assuming that, if panels transferred energy to DHW tank with maximum current during the whole day, it turns out that daily losses in cables would be $0.33 \mathrm{MJ}$. Due to the fact that this value is much bigger than the factual value, these losses can be ignored.

\section{Conclusion}

A few years ago, photovoltaic panels were considered a relatively expensive system of obtaining electricity. Now, when their price is much lower, they are also used as systems for preparing DHW. Furthermore, PVs working for the purpose of DHW do not require such devices (still expensive) as an inverter, charging regulator or battery. Apart from a relatively simple construction, they have multiple advantages which surpass solar systems based on solar collectors. They include: the possibility of being connected to electrical installation, obtaining energy even during winter, no need to worry about overheating water in the installation or lack of operational costs of circulation pump or of covering energy losses in cables connecting solar system with DHW tank. The only disadvantage is a relatively big surface necessary to install them.

This paper shows that the process of selecting panels for DHW installation is not complicated. Having precise insolation data, it is possible to obtain very reliable results. A significant issue in the calculation process is the volume of accumulation tank that allows to accumulate energy surpluses from at least one day. A bigger DHW tank allows to accumulate energy during sunny days and store it for cloudy days. However, large over dimensioning generates unnecessarily big heat losses from the tank's surface. One of the most important aspects in the process of selecting panels is determining the criterion for choosing the installation's power. 3 variants have been suggested in this paper. The first one, covering the smallest part of DHW demand will be an installation with the shortest payback time, but it requires a full year of work of another heating device. The other proposition allows to cover DHW requirements for the whole year. However, it is the least profitable. Furthermore, in the discussed case, the area occupied by panels would exceed $160 \mathrm{~m}^{2}$. However, it does not require an interference of another heating device in the process of preparing DHW and it allows to use a significant surplus of energy to cover electricity needs of a house. The last proposition is used in houses with a non-automated heating installation. In such a case, the PV installation enables a self-operating preparation of DHW outside the heating season (during summer).

\section{References}

1. K. Stanisz, District Heating, Heating, Ventilation, 41, 9, (2010, in Polish)

2. The Ordinance of the Minister of Transport, Construction and Maritime Economy of 5 July 2013 amending the ordinance on technical conditions which must be fulfilled by buildings and their locations, Journal of Laws of 13/8/2013, No. 926 (in Polish)

3. The Ordinance of the Minister of Infrastructure of 3 June 2013 on the methodology for calculating the energy performance of buildings and flats or parts of building constituting an independent technical and functional entity and the method of drawing up and samples of their energy performance certificates, Journal of Laws No. 2014, item 888 (in Polish)

4. J. Zimny, Renewable sources of energy in energyefficient constructions, (Polish Geothermal Association, Krakow, 2010, in Polish) 
5. E. Kostowski, Exercises on heat transfer, (Silesian University of Technology Publishing House, Gliwice, 2006, in Polish)

6. Emission factors and calorific values of fuel as well as typical meteorological years and statistical climate data for energy performance calculations. http://mib.gov.pl/2-

wskazniki_emisji_wartosci_opalowe_paliwa.htm\#, (in Polish)

7. J. Dopke, Calculating the number of heating degreedays according to the method of Eurostat, (ogrzewnictwo.pl, 2010, in Polish)

8. D. G. Erbs, S.A. Klein, W. A. Beckman, Estimation of degree-days and ambient temperature bin data from monthly average temperature, ASHRAE J, June, (1983) 